\title{
Characterization of the Advanced Stirling Radioisotope Generator EU2
}

\author{
Edward J. Lewandowski ${ }^{1}$, Salvatore M. Oriti ${ }^{2}$ and Nicholas A. Schifer ${ }^{2}$ \\ NASA Glenn Research Center, 21000 Brookpark Rd., Cleveland, OH 44135
}

\begin{abstract}
Significant progress was made developing the Advanced Stirling Radioisotope Generator (ASRG), a 140-watt radioisotope power system. While the ASRG flight development project has ended, the hardware that was designed and built under the project is continuing to be tested to support future Stirling-based power system development. NASA GRC recently completed the assembly of the ASRG Engineering Unit 2 (EU2). The ASRG EU2 consists of the first pair of Sunpower's ASC-E3 Stirling convertors mounted in an aluminum housing, and Lockheed Martin's Engineering Development Unit (EDU) 4 controller (a fourth generation controller). The ASC-E3 convertors and Generator Housing Assembly (GHA) closely match the intended ASRG Qualification Unit flight design. A series of tests were conducted to characterize the EU2, its controller, and the convertors in the flight-like GHA. The GHA contained an argon cover gas for these tests. The tests included: measurement of convertor, controller, and generator performance and efficiency, quantification of control authority of the controller, disturbance force measurement with varying piston phase and piston amplitude, and measurement of the effect of spacecraft DC bus voltage on EU2 performance. The results of these tests are discussed and summarized, providing a basic understanding of EU2 characteristics and the performance and capability of the EDU 4 controller.
\end{abstract}

\section{Nomenclature}

$F_{A}, F_{B}=$ Total dynamic force for ASC A, ASC B (N); sum of piston and displacer inertial forces

$F_{D} \quad=$ Disturbance force $(\mathrm{N})$

$F_{d A}, F_{d B}=$ Displacer inertial force for ASC A, ASC B (N)

$F_{p A}, F_{p B}=$ Piston inertial force for ASC A, ASC B (N)

$\Phi_{\mathrm{dA}}, \Phi_{\mathrm{dB}}=$ Displacer to piston phase angle for ASC A, ASC B $\left(^{\circ}\right)$

$\Phi_{\mathrm{B}} / \mathrm{A}=$ Relative phase angle between ASC A and ASC B dynamic forces $\left(^{\circ}\right)$

\section{Introduction}

$\mathrm{N}$ ASA continues to make progress on maturing Stirling-based energy conversion technology for future space missions. By offering the potential of high efficiency, low heat rejection, and low mass, Stirling power systems enable some deep space missions. The Department of Energy (DOE) and NASA made significant progress developing the Advanced Stirling Radioisotope Generator (ASRG), until the flight development project was terminated in late 2013. NASA Glenn Research Center (GRC) then contracted with Lockheed Martin (LM) to complete two engineering level ASC Controller Units (ACUs) known as Engineering Development Unit (EDU) 4.0 and 4.1, based on the flight ACU design. The controllers were delivered to GRC in 2014. These controllers plus hardware from the ASRG flight development contract were integrated into the ASRG Engineering Unit 2 (EU2). While ASRG flight development has ended, hardware from the ASRG project is being put on test to support future Stirling-based power system development. ${ }^{1}$ Although future flight hardware may not be identical to the hardware that was developed under the ASRG flight development project, many components will likely be similar, and system architectures may have heritage to ASRG.

This paper describes a series of tests conducted to characterize the EU2, its controller, and the convertors in the flight-like GHA. The GHA contained an argon cover gas for these tests. The tests included: measurement of

\footnotetext{
${ }^{1}$ Project Lead Engineer, Thermal Energy Conversion Branch, 21000 Brookpark Rd., AIAA Senior Member.

${ }^{2}$ Mechanical Engineer, Thermal Energy Conversion Branch, 21000 Brookpark Rd.
}

1

American Institute of Aeronautics and Astronautics 
convertor, controller, and generator performance and efficiency, quantification of control authority of the controller, disturbance force measurement with varying piston phase and piston amplitude, and measurement of the effect of spacecraft DC bus voltage on EU2 performance. The results of these tests provide a basic understanding of EU2 characteristics and the performance and capability of the EDU 4 controller.

\section{The ASRG EU2}

The ASRG EU2 is based on the ASRG flight design. Figure 1 shows a diagram of the ASRG flight unit, as designed by LM under contract to the Department of Energy. The ASRG contains two Advanced Stirling Convertors (ASCs) secured to one another with an interconnect tube. A General Purpose Heat Source (GPHS) module is held against each ASC heat collector to provide the heat input. The cold-side adapter flanges (CSAFs) conduct waste heat rejected from the convertors to the beryllium housing and fins, for radiation in a vacuum environment or convection to air. During ground operations argon fills the housing, sealed by o-rings and gaskets. A gas management valve allows access to the argon. A pressure relief device is provided to vent the argon during launch as the surrounding air pressure approaches the vacuum of space, improving effectiveness of the insulation that surrounds the heat

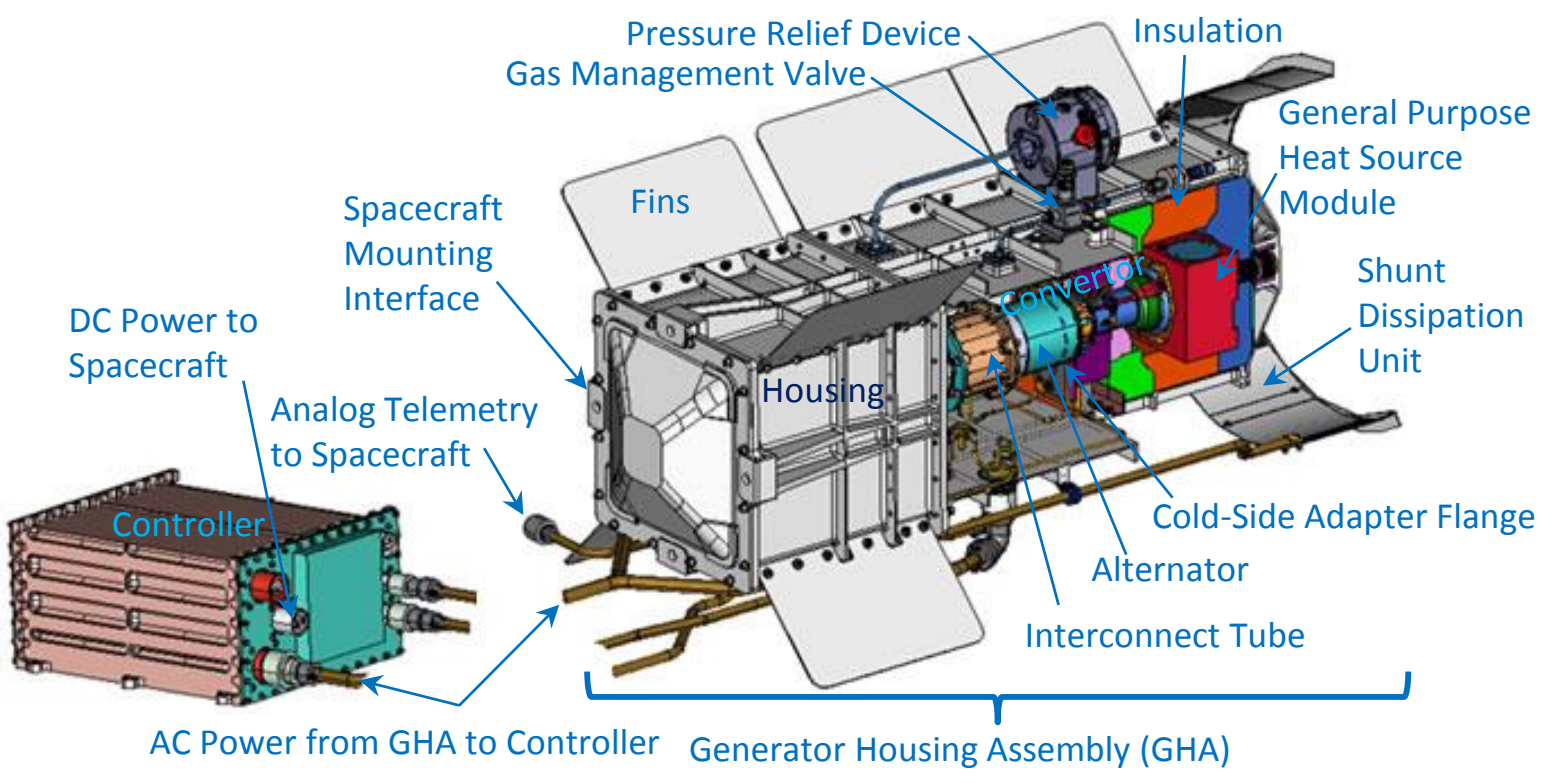

Figure 1. Diagram of the ASRG flight design.

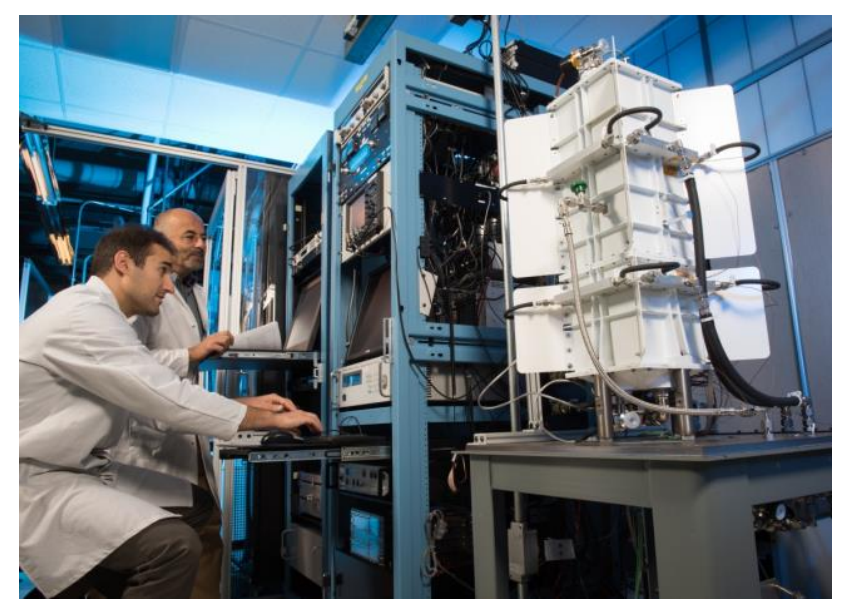

Figure 2. The ASRG EU2 under test in NASA GRC's Stirling Research Laboratory. source. The controller is remotely mounted in a location determined by the mission and connected electrically to the generator housing assembly (GHA) via cables. Connectors on the housing and controller provide electrical interfaces to the alternators, sensors, power input and output, control, and telemetry. The GHA is secured to a spacecraft interface or support via four mounting tabs on one end of the GHA.

The ASRG EU2 consists of the first pair of Sunpower ASC-E3 convertors (ASC-E3 \#1 and \#2), LM's EDU 4.1 controller (a fourth generation controller), and an aluminum housing. In this paper ASC-E3 \#1 is identified as ASC A, the inboard convertor, and ASC-E3 \#2 is ASC B, the outboard convertor. The integration of these convertors into the GHA, 
which closely matches the intended electrically heated ASRG Qualification Unit design, is discussed in Ref. 2.

\section{A. The EDU 4 Controller}

The controller is a significant component of the ASRG system, and it must perform several critical functions in any Stirling-based space power system. LM has evolved the controller design over the past several years to reach the level of a flight-like design. The ASRG controller functions include: ${ }^{3}$

- rectifying the $\mathrm{AC}$ power from the Stirling convertors

- synchronizing the two convertors to reduce disturbance force

- controlling the convertors' operating frequency and voltage (which then controls the piston amplitude)

- maintaining piston amplitude and hot-end temperature within desired ranges

- providing power to the spacecraft's DC power bus over a voltage range, with capability to handle overvoltage and under-voltage conditions

- receiving and responding to commands from the spacecraft

- providing telemetry to the spacecraft

- incorporating fault management functionality at the controller box level and integrating into the spacecraft's fault management system.

The controller uses power electronics technology to eliminate the need for tuning capacitors to compensate for alternator inductance, thereby reducing mass and improving reliability. It incorporates high-frequency pulse-width modulated (PWM) switching of an H-bridge to control the convertors. ${ }^{4}$ The controller algorithms and other functionality are implemented using field programmable gate arrays (FPGAs).

The ASRG EU incorporated EDU 1, a first generation controller. ${ }^{5}$ As an early implementation of a Stirling convertor controller for a space radioisotope system, it differs in many ways from the EDU 4 design. The EDU 1 controller included a temperature control loop and piston stroke limiting, features which are not in the EDU 4. There are many other changes as well, which further underscores the importance of characterizing the EU2 with the EDU 4.1 ACU. Additionally, EU testing uncovered a number of EDU 1-related issues. Some of these findings included:

- The piston amplitude was not steady but varied from cycle to cycle. This piston amplitude "jitter" was resolved by a change to how the control algorithm was coded.

- Operating frequency resolution was too coarse, so the operating frequency could not be set to the recommended value of $102.2 \mathrm{~Hz}$. This was resolved by improving the resolution of controller variables.

- There was a phase difference of several degrees between controller cards 1 and 2, which each controlled one of the convertors. As a result, the dynamic forces from the two convertor pistons were not cancelled. This was resolved by improving the controller card synchronization design.

- EDU 1's ASC voltage setpoint resolution by design was $1 / 8 \mathrm{~V}$. Tests showed this was too coarse and did not permit the fine adjustment likely needed at some points in the mission. Later controllers significantly improved resolution.

- There was inaccuracy in some of the telemetry. This was corrected in later controllers.

- Changing DC bus voltage resulted in a higher than allowable change in the hot-end temperature. This was resolved with control algorithm improvements in later controllers.

- There was a slow drift in control output. This was resolved with several design improvements to later controllers.

Extensive effort went into determining root causes of the

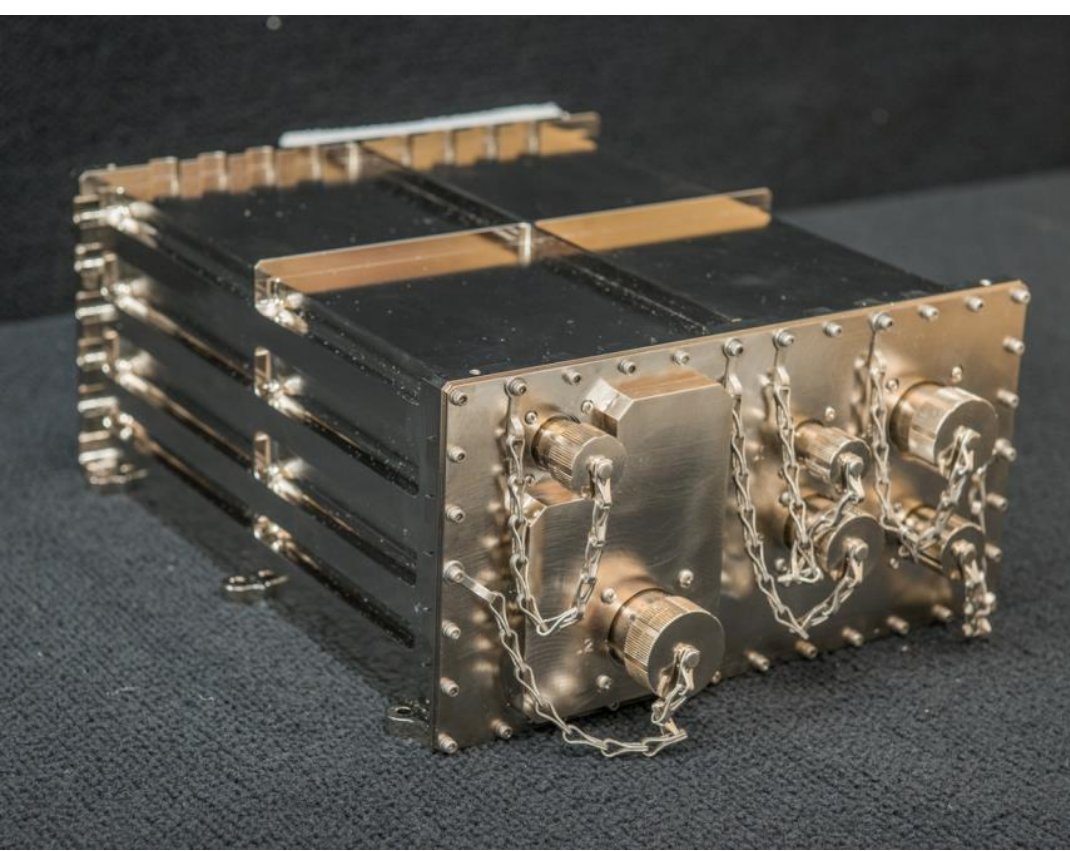

Figure 3. Lockheed Martin's EDU 4 controller. 
above-mentioned issues, both at GRC and at LM. Subsequent to the EDU 1 ACU build, LM built and tested several generations of controllers (EDU 2, EDU 2+, EDU 3, and EDU 4). EU2 characterization tests confirmed that these issues have been resolved, and in some cases provided data to quantify EDU 4 capability, which will be discussed later in this paper.

\section{ASRG EU2 Characterization Test Results}

This section summarizes ASRG EU2 characterization test results. The characterization tests were selected from EU tests that were found to be the most informative for understanding generator behavior.

\section{A. Overview of ASRG EU2 Characterization Tests}

Table I summarizes the tests that were conducted on the EU and the EU2. Some of the results of EU testing have been published previously, and can be referenced for comparison to EU2 results. ${ }^{6}$

Table I. Tests conducted with the ASRG EU and EU2.

\begin{tabular}{|c|c|c|c|}
\hline & Test & ASRG EU & ASRG EU2 \\
\hline \multirow{3}{*}{ 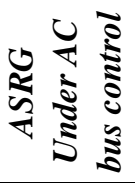 } & AC bus voltage variation & $\mathrm{X}$ & \\
\hline & Heat input variation & $\mathrm{X}$ & \\
\hline & Cold-end and pressure vessel temperature variation & $\mathrm{X}$ & \\
\hline \multirow{12}{*}{ 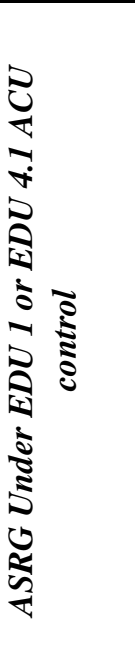 } & Performance test & & $\mathrm{X}$ \\
\hline & ASC voltage setpoint variation & $\mathrm{X}$ & $\mathrm{X}$ \\
\hline & DC bus voltage variation & $\mathrm{X}$ & $\mathrm{X}$ \\
\hline & Heat input variation & $\mathrm{X}$ & \\
\hline & Natural convection cooling test & $\mathrm{X}$ & \\
\hline & Core loss test & $\mathrm{X}$ & \\
\hline & ASC control stability & $\mathrm{X}$ & $\mathrm{X}$ \\
\hline & ACU stability and drift & $\mathrm{X}$ & \\
\hline & ASC voltage setpoint command resolution & $\mathrm{X}$ & $\mathrm{X}$ \\
\hline & Operating frequency command resolution & $\mathrm{X}$ & \\
\hline & Controller card interaction test & $\mathrm{X}$ & $\mathrm{X}$ \\
\hline & Extended operation & $\mathrm{X}$ & \\
\hline
\end{tabular}

Tests were conducted on the EU2 with two different control configurations: ACU control and AC bus control. Figure 4 shows the EU2 configuration with the ACU. The EDU 4.1 was used to control the two convertors in the GHA, and the spacecraft DC bus was simulated by a DC electronic load plus capacitors.

Figure 5 shows the AC bus control configuration. In this configuration, the ACU was replaced with tuning capacitors and a simulated AC bus, which was connected directly to the convertors in the GHA. This configuration more closely matched how the convertors were tested prior to integration into the GHA. The AC bus control configuration was used to provide ASC and GHA performance data independent of the ACU. Data from this configuration allowed for comparison to convertor-level performance test data, to quantify the effect of the ACU, and to

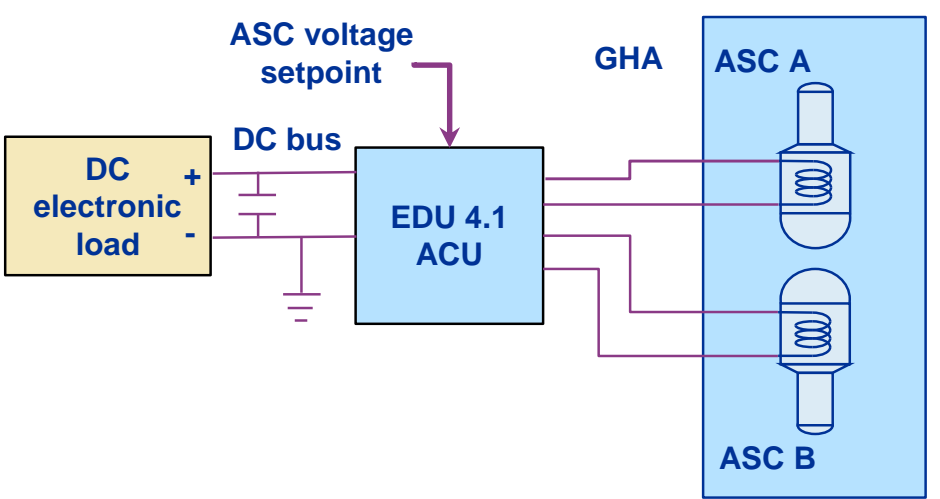

Figure 4. ACU control configuration for ASRG EU2 testing. 
provide a benchmark for assessing the ACU's performance as a convertor controller.

For the tests described in this paper, the GHA was operated with an argon cover gas. The argon cover gas was intended to be used for much of ASRG ground operations and would have been vented during launch. As noted in Ref. 2, the GHA was assembled with a thin alumina disk between the convertor's heat collector and the electric heat source. This interface created too much thermal resistance in a vacuum environment, and the alumina disk will be replaced with graphitic material in the future to provide adequate heat transfer in vacuum.

\section{B. ASRG EU2 Power Output}

The ASRG performance specification requires the generator to produce a minimum of $130 \mathrm{~W}_{\mathrm{e}}$ at the beginning of mission (BOM) reference operating point, with $244 \mathrm{~W}_{\text {th }}$ input from each GPHS module. The BOM reference operating point is defined as the point when the ASRG reaches equilibrium just after launch, in deep space vacuum environment, with a $4 \mathrm{~K}$ sink temperature and no solar flux. This condition results in about a $38{ }^{\circ} \mathrm{C}$ rejection temperature at the convertor, and is commonly referred to as the "low reject" point.

To assess ASRG EU2 performance relative to this power output requirement, the heat input from each heat source was increased by about $30 \mathrm{~W}_{\text {th }}$ to compensate for the thermal losses associated with operating with an argon cover gas in the GHA. Table II summarizes the ASRG EU2 performance at the BOM low reject operating point and a nominal spacecraft DC bus voltage of $28 \mathrm{~V}$.

Table II. ASRG EU2 performance at BOM low reject operating point.

\begin{tabular}{|l|l|c|c|}
\hline \multicolumn{1}{|c|}{ Parameter } & Units & Value \\
& & ASC A & ASC B \\
\hline Electric heat source power input (gross heat input) & $\mathrm{W}_{\text {th }}$ & 277.3 & 275.4 \\
\hline Hot-end temperature & ${ }^{\circ} \mathrm{C}$ & 760 & 760 \\
\hline Rejection temperature & ${ }^{\circ} \mathrm{C}$ & 37 & 38 \\
\hline Alternator power output & $\mathrm{W}_{\mathrm{e}}$ & 77.9 & 82.3 \\
\hline Convertor gross efficiency (alternator power/gross heat input) & $\%$ & 28.1 & 29.9 \\
\hline ACU Power Input (sum of alternator power output) & $\mathrm{W}_{\mathrm{e}}$ & & 160.2 \\
\hline ACU Power Consumption & $\mathrm{W}_{\mathrm{e}}$ & & 20.6 \\
\hline DC Output Power & $\mathrm{W}_{\mathrm{e}}$ & & \multicolumn{2}{c|}{139.6} \\
\hline
\end{tabular}

The ASRG EU2 produced $139.6 \mathrm{~W}_{\mathrm{e}}$ of power at the BOM low reject operating point. Based on this result, we would expect that a generator built to the ASRG flight design would meet the $130 \mathrm{~W}_{\mathrm{e}}$ power output requirement with margin.

Note that the gross heat input was actually set slightly higher than the $30 \mathrm{~W}_{\text {th }}$ delta to compensate for the argon cover gas (33.3 $\mathrm{W}_{\text {th }}$ for ASC A and 31.4 $\mathrm{W}_{\text {th }}$ for ASC B). This is because the convertor operating point for this test

American Institute of Aeronautics and Astronautics 
was actually set to match previously measured ASC performance data at BOM low reject. This test point incorporated the results of multidimensional numerical modeling validated by test data to accurately estimate convertor net heat input. ${ }^{7}$ Had the gross heat input been decreased to $274 \mathrm{~W}_{\text {th }}$, the DC power output would have decreased by only $1.3 \mathrm{~W}_{\mathrm{e}}$ to $138.3 \mathrm{~W}_{\mathrm{e}}$, and still would have had significant margin to the specification.

It should also be noted that the ASC A convertor's power output was only $77.9 \mathrm{~W}_{\mathrm{e}}$, compared with ASC B's output of $82.3 \mathrm{~W}_{\mathrm{e}}$. ASC A, which is more specifically ASC-E3 \#1, is the lowest efficiency ASC-E3 convertor produced to date. ASC B's performance is more typical of ASC-E3 convertors, and so the EU2 underestimates the performance that would be achieved with nominal ASC convertors.

\section{Convertor Stability Under ACU Control}

One of the controller functions mentioned earlier is that the controller must control each Stirling convertor so that the piston maintains a steady amplitude from cycle to cycle, and the mean piston position does not shift in or out. Piston amplitude variation from cycle to cycle results in a higher disturbance force. This can appear as "jitter" in piston position signals and was observed when the ASRG EU was operated with the EDU 1 controller. Algorithm improvements since EDU 1 have addressed the jitter issue.

Convertor stability under AC bus control is often used as a reference standard of comparison. A digital controller should be able to control a convertor similar to an AC bus controller.

To evaluate the control stability of EDU 4.1, the EU2 was operated at the same convertor operating point under AC bus control and then under ACU control (Figs. 4 and 5). Piston position was recorded every cycle for 1 minute (over 6,100 cycles). The amplitude and mean position were calculated for each cycle and then plotted on frequency distribution histograms (Fig. 6). Figure 9 provides an example of how piston amplitude varies from cycle to cycle.

Figure 6 shows that EDU 4.1 had better control stability over piston position than an AC bus controller. There

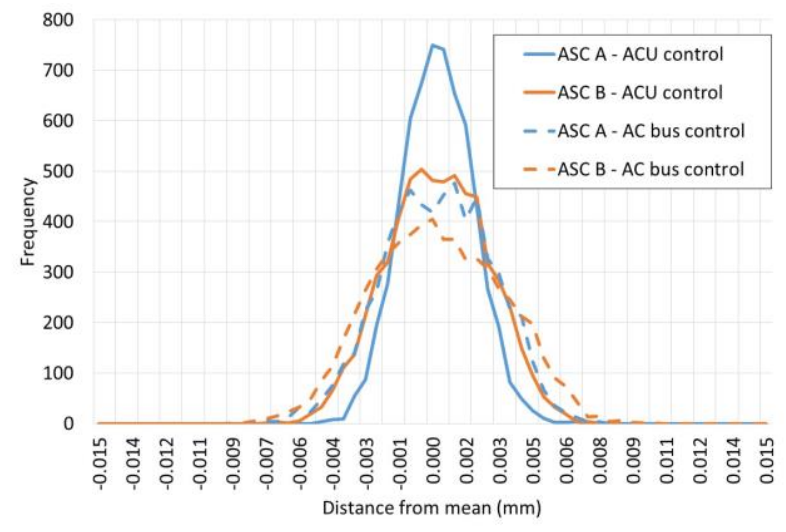

Figure 6a. Piston amplitude histogram.

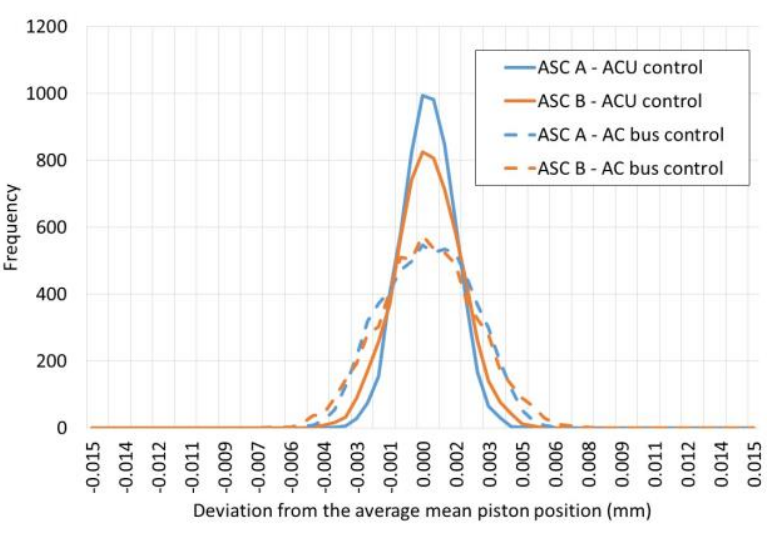

Figure 6b. Mean piston position histogram.

was less cycle-to-cycle variability in amplitude and mean piston position with the ACU. Table III shows the standard deviation for piston amplitude and mean piston position, with ACU control having at least a $22 \%$ reduction in standard deviation. While this result may at first seem surprising, one must realize that the analog AC bus control system adds its own bandwidth limitations and dynamics. It is possible for a properly designed digital ACU controller, with its high frequency control loops, fine parameter resolution, and greater algorithm flexibility, to achieve superior stability vs. an analog controller.

Table III. Piston amplitude and mean piston position standard deviations (mm).

\begin{tabular}{|cc|c|c|c|}
\cline { 3 - 5 } \multicolumn{1}{c|}{} & & AC bus control & ACU control & \% reduction \\
\hline \multirow{2}{*}{ Piston amplitude } & ASC A & 0.0024 & 0.0016 & $35 \%$ \\
& ASC B & 0.0029 & 0.0023 & $22 \%$ \\
\hline \multirow{2}{*}{ Mean piston position } & ASC A & 0.0020 & 0.0012 & $41 \%$ \\
& ASC B & 0.0022 & 0.0015 & $31 \%$ \\
\hline
\end{tabular}




\section{ASC Voltage Setpoint Command Resolution}

The primary control input for the ASRG is the ASC voltage setpoint. There is one ASC voltage setpoint for each convertor. The ASC voltage setpoint directly determines the piston amplitude, although the ASC voltage setpoint does not fix the piston amplitude, as piston amplitude can vary slightly for a given ASC voltage setpoint as other convertor parameters vary, such as the rejection temperature. (Note that the ASC voltage setpoint controls the convertor operating point, not the spacecraft DC bus voltage. The DC bus voltage is regulated on the spacecraft side of the electrical interface. See Fig. 4.)

The operator would use the ASC voltage setpoint to maintain the hot-end temperature within a desired operating band as the radioisotope fuel decays or as the generator's operating environment, specifically rejection temperature, changes. As the fuel decays, less heat enters the Stirling convertor, and hot-end temperature decreases. Hot-end temperature can be increased by decreasing piston amplitude, maintaining generator efficiency and maximizing output power.

A reason that the ASC voltage might be adjusted is to minimize the disturbance force from the generator (see Sec. G). Matching the amplitudes of the two convertors tends to minimize the disturbance force.

The resolution of ASC voltage setpoint command determines how finely the hot-end temperature and piston amplitude can be controlled. Having fine resolution also helps with margin uncertainty analysis. The control resolution should be fine enough that additional margin allowance for the command resolution does not need to be added when allowing for uncertainties in the system. For example, the hot-end temperature cannot exceed a certain limit, but since there is no direct measurement of hot-end temperature, it is controlled open loop. In determining the allowable range for the ASC voltage setpoint at a particular time in a mission, allowance needs to be made for uncertainties in factors that affect hot-end temperature in order to insure that the maximum temperature limit is not exceeded. A coarse command resolution could limit how well the operating point can be optimized.

The EDU 4.1 ACU ASC voltage setpoint has a resolution of $0.008 \mathrm{~V}$. A test was conducted where the ASC voltage setpoint was first decreased by $0.008 \mathrm{~V}$, and then 173 minutes later, was increased back to the original setpoint. The system response to this command input would be first an increase in hot-end temperature then a decrease in hot-end temperature. The test results are shown in Fig. 7.

The test was conducted during a slow transient where hot-end temperatures were slowly decreasing $(\sim 0.1$ ${ }^{\circ} \mathrm{C} /$ hour). In spite of the downward drift in hot-end temperature, both hot-end temperatures increased slightly when the ASC voltage setpoint was decreased by $0.008 \mathrm{~V}$. In steady-state, this might result in perhaps a one degree change in hot-end temperature, which is adequate resolution for power system control.

\section{E. ASC Voltage Setpoint Variation}

To determine specific ASC voltage setpoint commands during operation, the effect of an ASC voltage setpoint change on piston amplitude and hot-end temperature would be characterized under the various operating conditions expected during a mission. With the generator performance mapped out during ground operations, operators could then determine appropriate setpoint commands in response to slow changes like fuel decay, or fast changes like a launch transient.

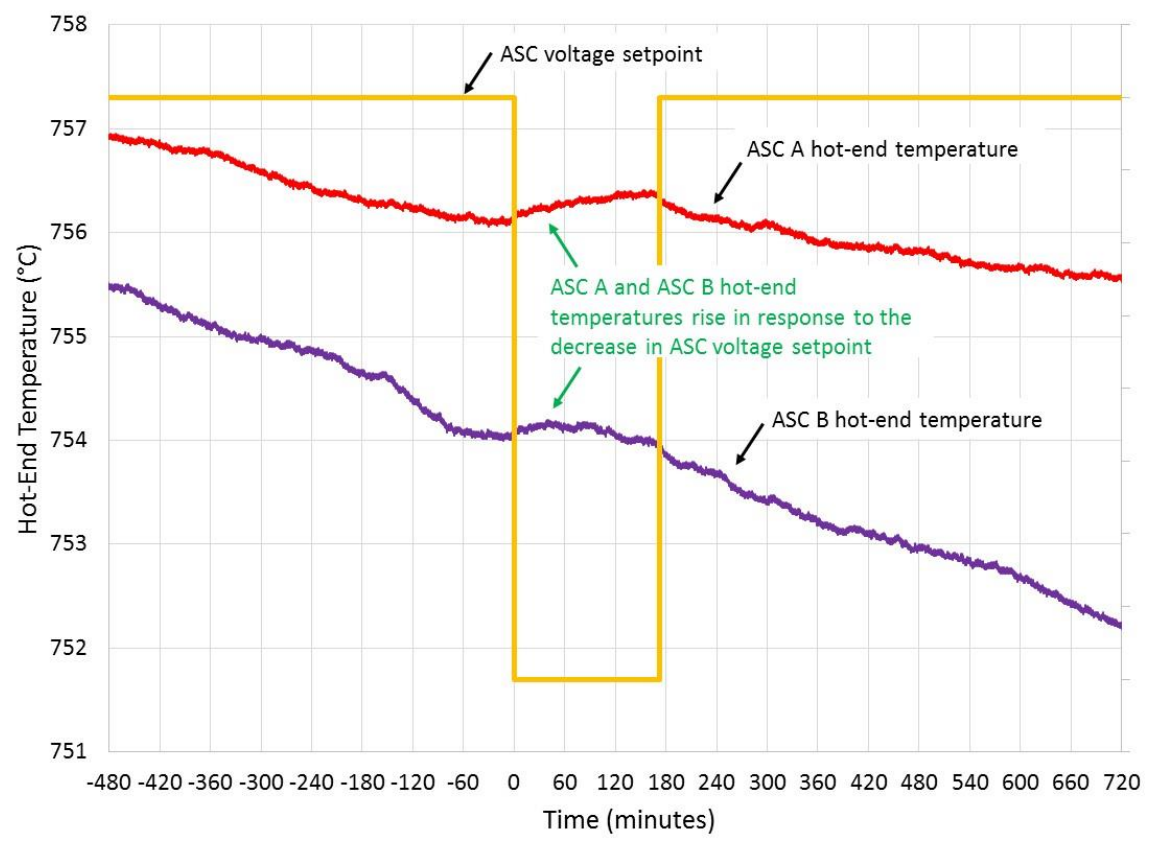

Figure 7. Effect of a small change in ASC voltage setpoint on ASC hot-end temperature.

American Institute of Aeronautics and Astronautics 
A test was conducted to characterize the generator response to a large step change in ASC voltage setpoint. This test was similar to the ASC voltage setpoint command resolution test, except that the step size was closer to a change that might be made more typically during operation. The ASC voltage setpoint was decreased by $0.40 \mathrm{~V}$ and allowed to approach steady-state. The next day the ASC voltage setpoint on ASC A was increased by $0.40 \mathrm{~V}$, ASC B's setpoint was increased a few hours later. The results are plotted in Fig. 8.

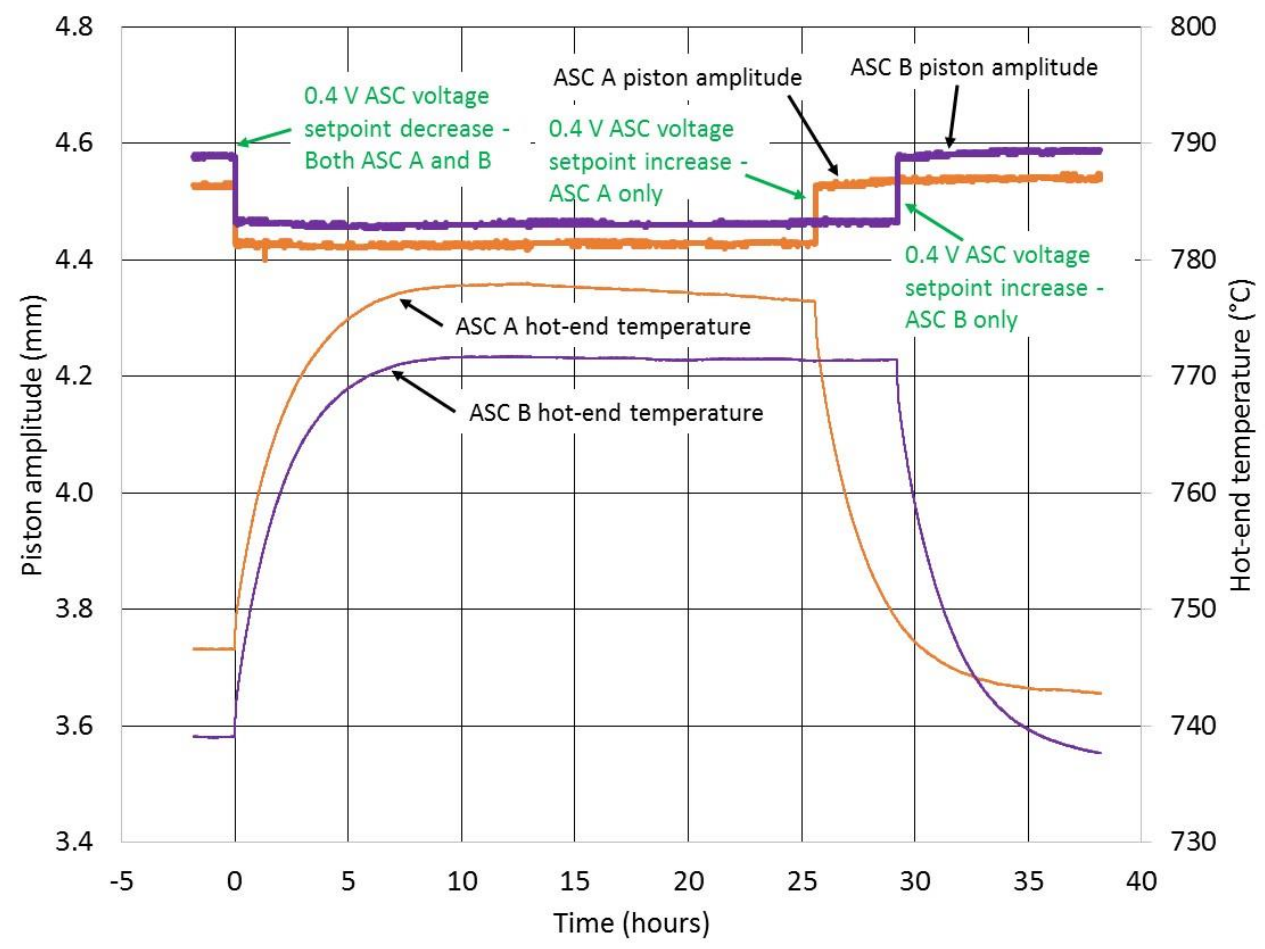

Figure 8. ASRG EU2 response to step changes in ASC voltage setpoint.

The step-change in ASC voltage setpoint resulted in an immediate decrease in piston amplitude, followed by a slower increase in hot-end temperature, which took about 10 hours to approach a new equilibrium point. A similar lag in hot-end temperature is seen when piston amplitude was later increased. The ASRG EU2's electric heat source has thermal inertia that is similar to that of a GPHS module, so this time response should be approximately what would be seen with a GPHS module. On the cold side, the current test configuration does not simulate the dynamics of heat rejection to a space environment. The EU2's aluminum housing as a lower thermal inertia than the beryllium housing, and more importantly, the heat rejection temperature was controlled with blocks attached to the housing. So the heat source transient may be reasonably simulated with the EU2 in this configuration, but the slower transient expected with a generator in a radiative deep space environment was not. Since the rejection temperature has a smaller effect on hot-end temperature, the hot-end temperature transient would differ only slightly in a representative deep space environment from the response shown in Fig. 8.

The piston amplitude cycle-by-cycle response to the step change is shown in Fig. 9 when the ASC voltage setpoint was increased by $0.4 \mathrm{~V}$ for ASC A only (corresponds to 26 hours in Fig. 8). This figure shows that ASC A's piston amplitude approached the steady state amplitude within two cycles, with a small overshoot and oscillation, then continued to rise slightly over the next approximately 30 cycles.

Over the next several hours, the piston amplitude increased some more due to the decrease in hot-end temperature, as seen in Fig. 8, between 26 and 35 hours for ASC A. Likewise, Fig. 8 shows the ASC A and ASC B piston amplitudes decreased slightly with increasing hot-end temperature between 1 and 10 hours. This additional change in piston amplitude is relatively small for the ASC-E3 convertors in this ASRG configuration. Other convertors tested in the Stirling Research Laboratory have shown different and larger response to the change in hotend temperature following the equivalent of an ASC voltage setpoint change. For example, the ASC-E convertors in the ASRG EU showed a decrease in piston amplitude in response to the hot-end temperature decrease. ${ }^{6}{ }^{\text {This }}$ difference in behavior is not unexpected, as convertor response to various inputs involves a complex interaction of a number of factors, and the way these factors interact can depend on the specific convertor design and hardware configurations. 


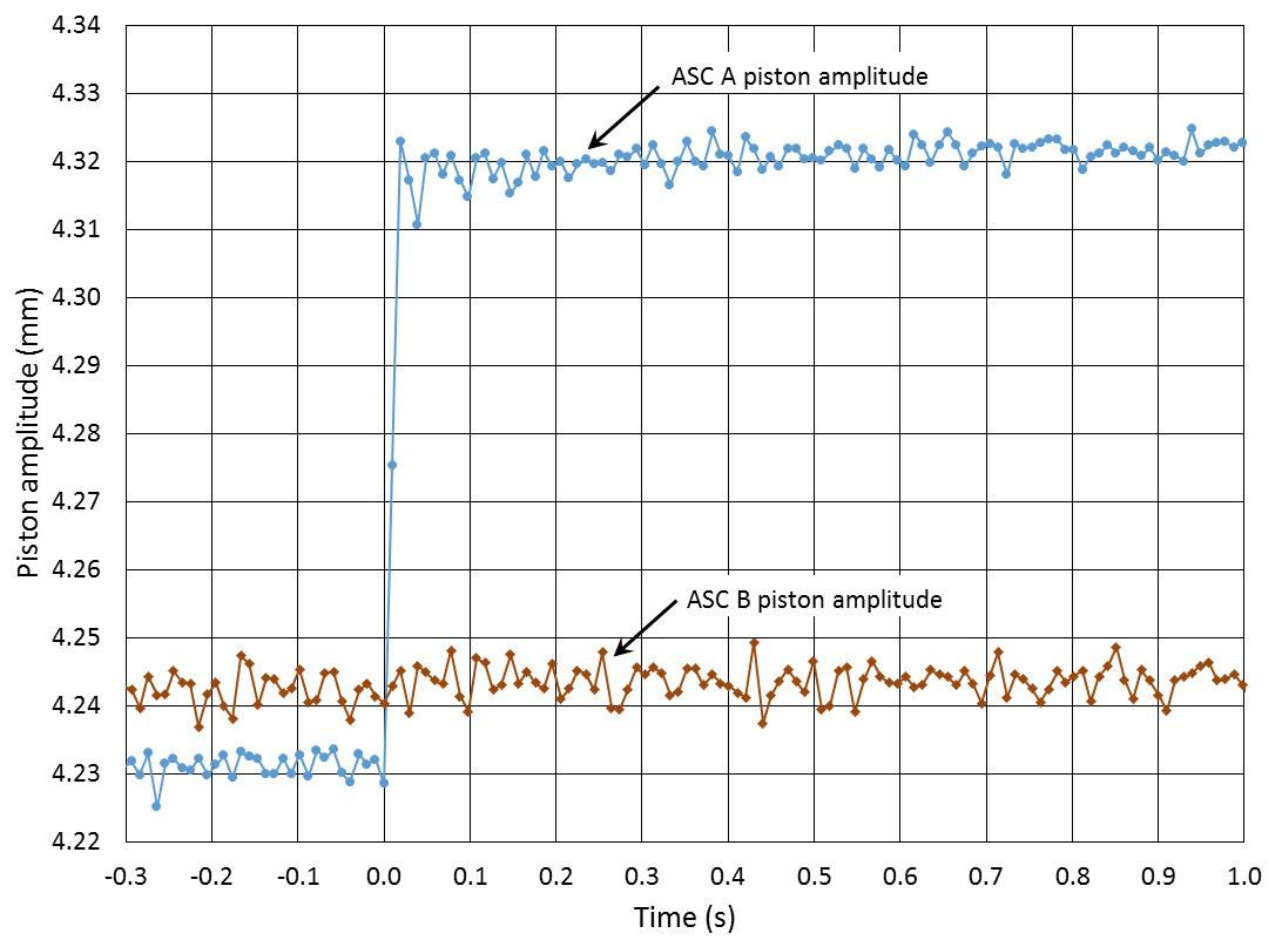

Figure 9. Piston amplitude response to a step change in ASC setpoint voltage.

Figure 9 also shows that when the ACU commanded a voltage setpoint change to ASC A only, the piston amplitude for the other convertor (ASC B) was unaffected. This indicates that there was no cross-talk between the two controller cards (where each controller card controls one convertor).

\section{F. DC Bus Voltage Variation}

Another external effect that was evaluated on the EU2 was how a change in the spacecraft DC bus voltage influenced the convertor operating point. Ideally, a change in the DC bus voltage would have no effect on the ASC operation. However, over part of the DC bus range, changing the DC bus voltage changes the DC voltage being applied to the ASC alternator terminals through the H-bridge. ${ }^{4}$ The controller algorithm compensates for most, but not all of the effect of the DC bus voltage change by adjusting the PWM duty cycle.

A test was conducted to quantify the change in hot-end temperature, ASC alternator voltage, and piston amplitude due to a change in the DC bus voltage over the nominal DC bus voltage range of 22 to $34 \mathrm{~V}$. The results are shown in Fig. 10. The DC bus voltage was first increased from 28.5 to $34.4 \mathrm{~V}$ in $2 \mathrm{~V}$ steps. The EU2 was left in this operating condition overnight to allow it to reach steady-state. Then the DC bus voltage was decreased back down to $28.5 \mathrm{~V}$, then down to $22.6 \mathrm{~V}$, and allowed to reach steady-state overnight. Finally, the DC bus voltage was increased back to $28.5 \mathrm{~V}$.

Sensitivities were calculated as the DC bus voltage changed from 28.5 to $34.4 \mathrm{~V}$. Two values were calculated, as the sensitivities were slightly different between ASC A and ASC B. Note also that the sensitivities will vary slightly depending on the generator operating point.

- Hot-end temperature sensitivity: -3.1 to $-3.2^{\circ} \mathrm{C} / \mathrm{V}$

- ASC voltage sensitivity: -0.024 to $-0.030 \mathrm{Vrms} / \mathrm{V}$

- ASC amplitude sensitivity: 0.009 to $0.012 \mathrm{~mm} / \mathrm{V}$

Overall, the effect of DC bus voltage change is small and could be part of the mission's considerations when interfacing to the ASRG. Further refinements to the DC bus voltage compensation algorithm could reduce the sensitivities. ${ }^{8}$ The EDU 4.1 sensitivities were significantly smaller than sensitivities observed during EU testing with EDU 1.

The data in Fig. 10 also show that between 28.5 and $22.6 \mathrm{~V}$, the effect of changing the DC bus voltage on the ASC operating point was much less. This is because below a certain spacecraft DC bus voltage, the controller does not decrease the DC voltage being applied to the ASC alternator terminals through the H-bridge. 


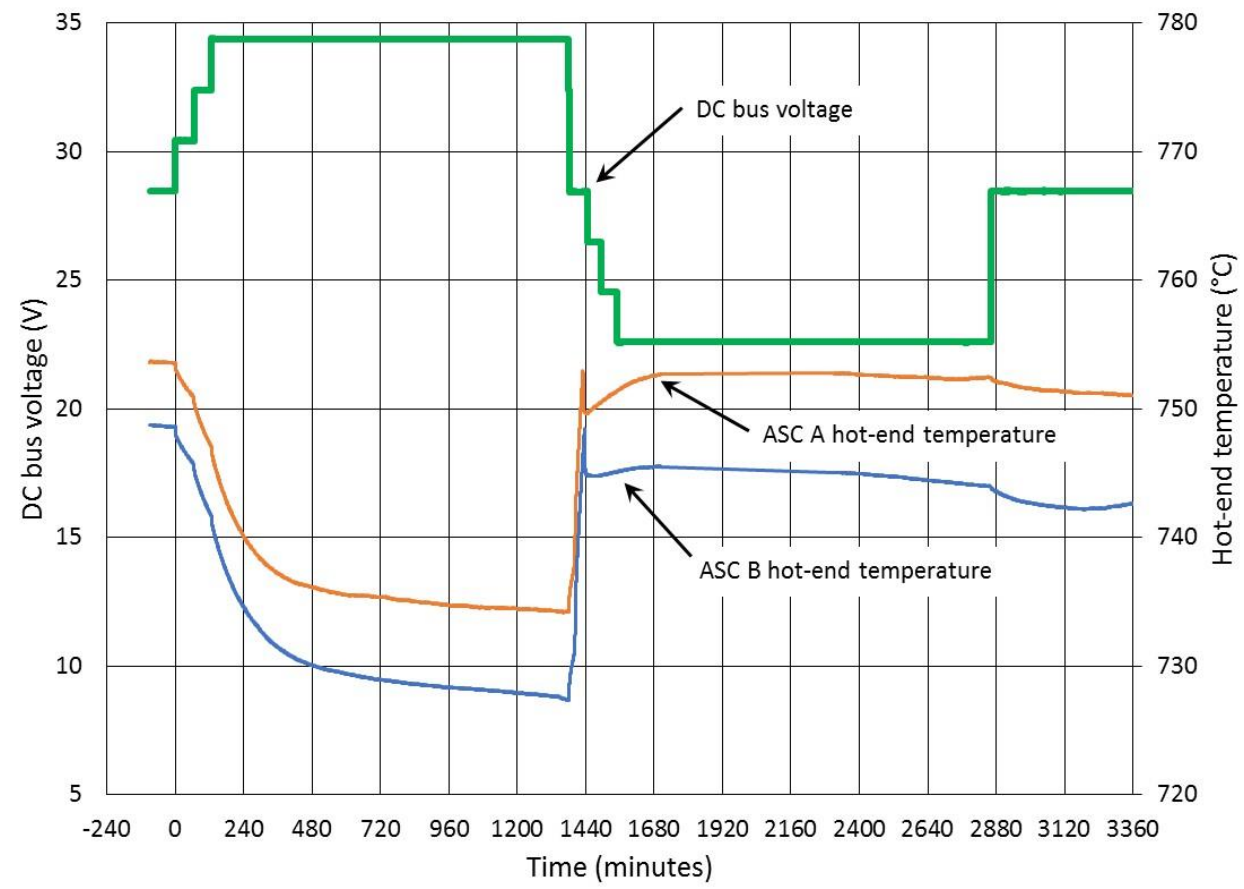

Figure 10. DC bus voltage variation test results.

In addition to affecting the ASC operating point, changing the spacecraft DC bus voltage also affects the ACU power consumption. When the DC bus voltage was increased from 28.5 to $34.4 \mathrm{~V}$, the ACU power consumption increased $2.0 \mathrm{~W}_{\mathrm{e}}$, from 20.4 to $22.5 \mathrm{~W}_{\mathrm{e}}$ (or $0.35 \mathrm{~W}_{\mathrm{e}}$ per one volt change in DC bus voltage). ACU power consumption was the lowest around $28 \mathrm{~V}$, and it increased as well when DC bus voltage was decreased to $22.6 \mathrm{~V}$.

\section{G. Disturbance Force}

The ASRG is a dynamic power system with moving parts that oscillate at $102.2 \mathrm{~Hz}$. Each moving part generates a sinusoidally-varying inertial force, and the sum of those forces approximately equals the disturbance force transmitted to the spacecraft. The actual force depends on the ASRG mounting interface and how the force is transmitted through the GHA. In the ASRG, the ASCs are operated with the pistons moving opposed to each other, so that the dynamic force from one ASC nominally cancels out the dynamic force from the other.

Figure 11 shows a phasor diagram of the inertial forces from the two convertors, with the residual force, $F_{D}$, as

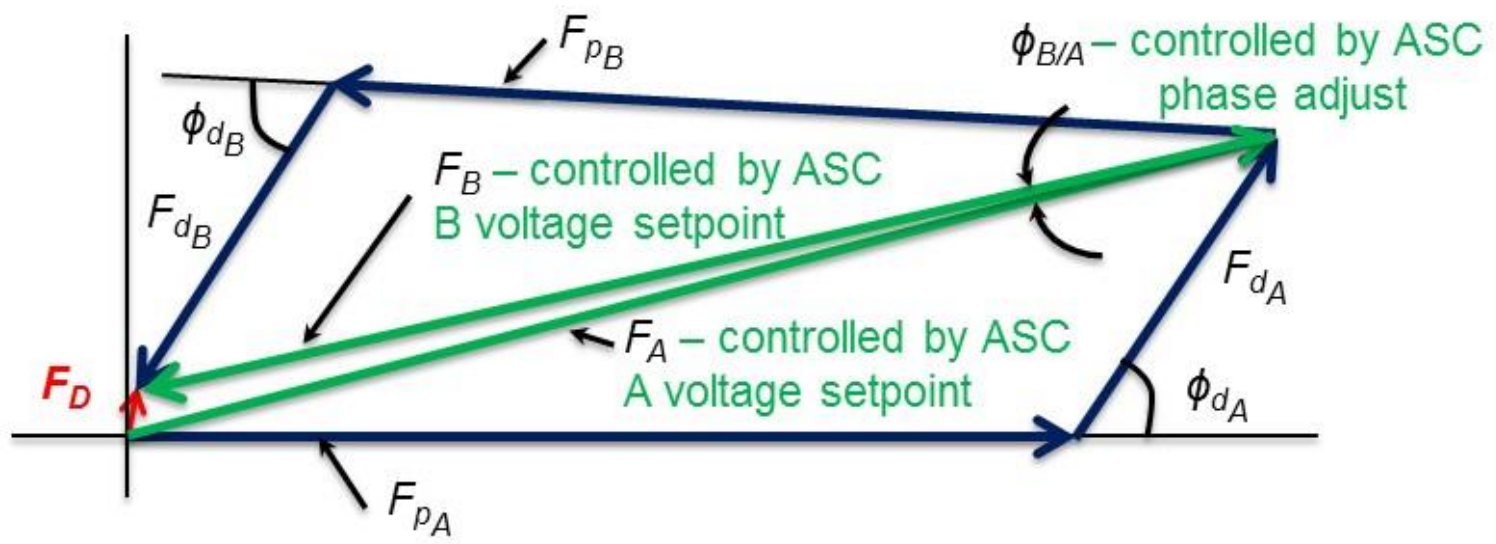

Figure 11. Phasor diagram of disturbance force as a sum of piston and displacer inertial forces. 
the disturbance force. The ASRG has three parameters that can be used to tune the system to reduce the disturbance force. The most important one is the ASC phase adjust, which controls the phase angle between the two convertors ( $\phi_{B / A}$ in Fig. 11). The other two parameters are the ASC voltage setpoints, which control the amplitudes of each convertor, and thus the magnitudes of the inertial forces. Since displacer amplitude generally increases with piston amplitude, increasing the ASC voltage setpoint increases both the displacer and piston inertial forces. Another parameter shown in Fig. 11 is the displacer phase angle, which determines the angle between the displacer and piston inertial forces, however this can only be changed during fabrication of the convertor.

A test was conducted in which the ASC phase adjust and the piston amplitudes were varied and the effect on disturbance force was measured (Fig. 12). First, the ASC phase adjust was increased to $14^{\circ}$, which resulted in an increase in disturbance force from 9 to $51 \mathrm{~N}$, exceeding the specification limit of $35 \mathrm{~N}$. Disturbance force increased $3.0 \mathrm{~N}$ per degree change in phase angle. The phase angle was then decreased below 0 to find the point of minimum disturbance force. This occurred at $-2.0^{\circ}$, and it reduced the force to $5.4 \mathrm{~N}$. The reason the minimum did not occur at $0^{\circ}$ is that the controller is setting the relative phase of the two ASC voltages to $0^{\circ}$, but because of manufacturing differences in the two convertors, the phase relationships between the voltage and piston motion are not identical.

With the inertial forces of the two convertors in phase, the amplitudes were adjusted to further reduce the disturbance force. It was found that decreasing ASC A voltage setpoint and thus ASC A piston amplitude reduced the disturbance to $2.1 \mathrm{~N}$. At this point the fundamental component of the disturbance force was reduced to less than the second harmonic. (Note that Fig. 12 it appears that the ASC A piston amplitude was reduced to less than ASC B piston amplitude to minimize the disturbance force. But it is likely that due to uncertainty in the amplitude measurement, the point of minimal disturbance force is where the piston amplitudes are in fact closely matched.)

Lastly, the piston amplitude of one convertor was decreased to measure the effect of piston amplitude on disturbance force. ASC B's piston amplitude was decreased from about 4.5 to $3.6 \mathrm{~mm}$, which increased the disturbance force to $34 \mathrm{~N}$. Expressed as a sensitivity, the disturbance force increased $38 \mathrm{~N}$ per mm change in piston amplitude.

The disturbance force test confirmed that control of phase angle is more important to minimizing disturbance force than matching piston amplitudes. The piston amplitude range that was tested exceeded the allowable steady state operating range, given hot-end temperature constraints.

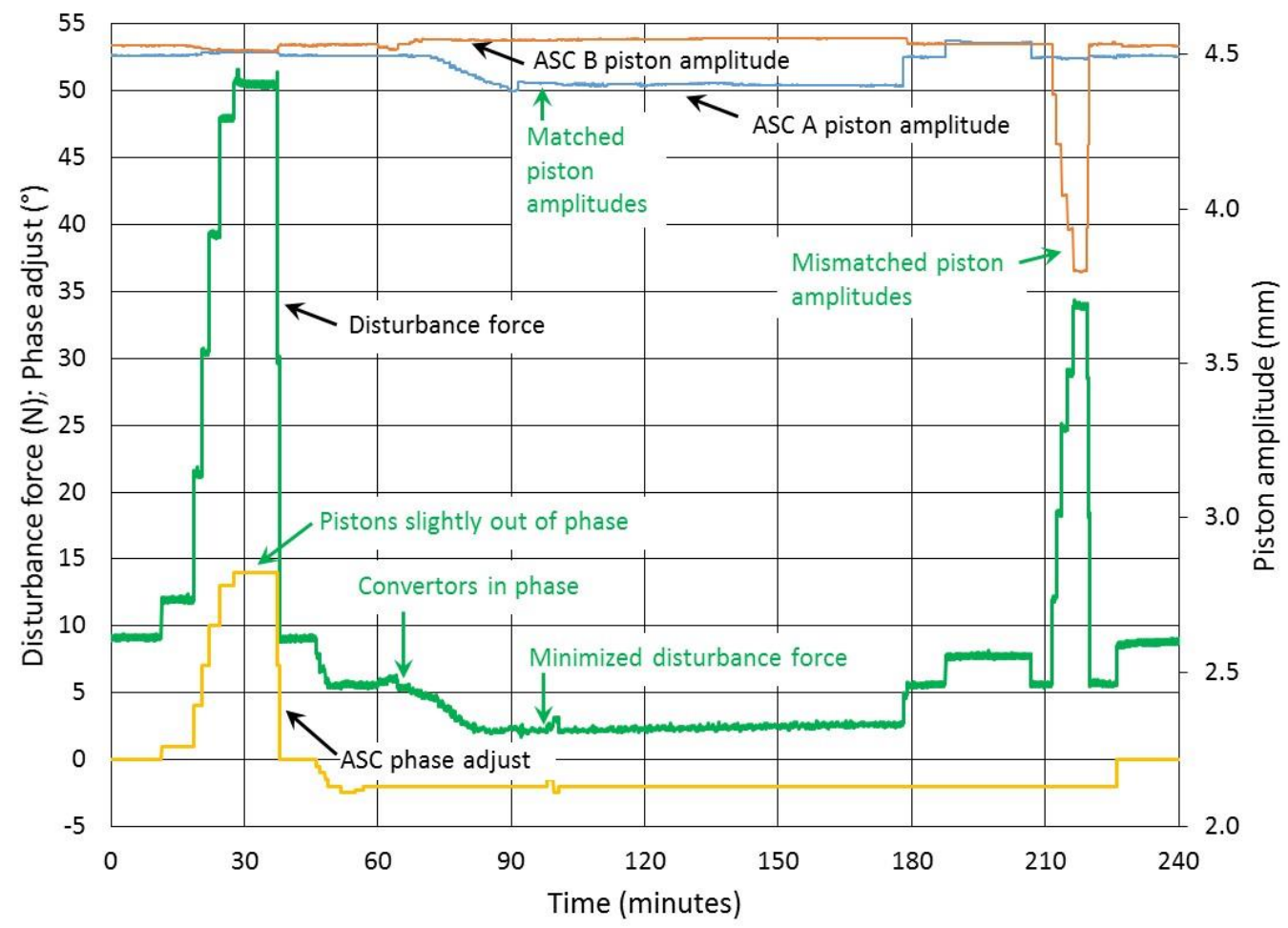

Figure 12. Effect of varying phase and piston amplitude on the disturbance force. 


\section{Conclusion}

The ASRG EU2, which is based on the ASRG flight design, has been an important test article for maturing Stirling system technology. Initial characterization of the ASRG EU2 has been completed, with test results that were as expected. The EDU 4.1 controller demonstrated stable performance with good convertor control that was even better than AC bus control. All of the issues that had been identified during early EU testing were shown to be resolved with the EU2 configuration.

\section{Acknowledgments}

The authors wish to acknowledge the staff of NASA GRC's Stirling Research Laboratory and personnel from Lockheed Martin, without whom the ASRG EU2 testing would not have been successful. This work was funded with the support of the NASA Science Mission Directorate and the Radioisotope Power Systems Program Office. Any opinions, findings, conclusions, or recommendations expressed in this article are those of the authors and do not necessarily reflect the views of NASA.

\section{References}

${ }^{1}$ Lewandowski, E. J., Bolotin, G.S., and Oriti, S.M., "Test Program for Stirling Radioisotope Generator Hardware at NASA

Glenn Research Center," Proceedings of the Twelfth International Energy Conversion Engineering Conference (IECEC 2014) AIAA, Cleveland, OH, 2014. AIAA 2014-3964.

${ }^{2}$ Oriti, S.M., "Advanced Stirling Radioisotope Generator Engineering Unit 2 (ASRG EU2) Final Assembly," Proceedings of the Nuclear and Emerging Technologies for Space 2015, Albuquerque, N.M., February 23-26, 2015.

${ }^{3}$ Brown, G., Wiser, J., Coe, M., and Chan, J., "Scalable Controller Concepts for High Power Nuclear Stirling Systems," Proceedings of the 65 th International Astronautical Conference, Toronto, CA, 2014. IAC-14-C3.5-C4.7.10x26290.

${ }^{4}$ Holliday, E.S., "Controller Computing a Virtual Tuning Capacitor for Controlling a Free-Piston Stirling Engine Driving a Linear Alternator," U.S. Patent 7,511,459, March 31, 2009.

${ }^{5}$ Leland, D. K., Priest, J. F., Keiter, D. E., and Schreiber, J. G., "Development of a Power Electronics Controller for the Advanced Stirling Radioisotope Generator," Proceedings of Fifth International Energy Conversion Engineering Conference (IECEC 2007), AIAA, St. Louis, Missouri, 2007.

${ }^{6}$ Lewandowski, E. J. and Schreiber, J. G., "Testing to Characterize the Advanced Stirling Radioisotope Generator Engineering Unit," Proceedings of the Eighth International Energy Conversion Engineering Conference (IECEC 2010) AIAA, Nashville, TN, 2010.

${ }^{7}$ Wilson, S.D., et al., "Overview of Heat Addition and Efficiency Predictions for an Advanced Stirling Convertor," Proceedings of the Ninth International Energy Conversion Engineering Conference (IECEC 2011), AIAA, San Diego, CA, 2011.

${ }^{8}$ Chan, T., Wiser, J., Brown, G., Florin, D., and Oriti, S.M., "System-Level Testing of the Advanced Stirling Radioisotope Generator Engineering Hardware," Proceedings of the Twelfth International Energy Conversion Engineering Conference (IECEC 2014) AIAA, Cleveland, OH, 2014. 